\title{
Abortion of acute ST segment elevation myocardial infarction after reperfusion: incidence, patients' characteristics, and prognosis
}

\author{
E J P Lamfers, T E H Hooghoudt, D P Hertzberger, A Schut, P W J Stolwijk, \\ F W A Verheugt
}

See end of article for authors' affiliations

Correspondence to Correspondence
Dr E J P Lamfers, Department of Cardiology, Canisius-Wilhelmina Hospital, PO Box 9015, 6500 GS Nijmegen, Netherlands:

ejp.lamfers@inter.nl.net

Accepted

9 December 2002

\begin{abstract}
Objectives: To study the incidence and patient characteristics of aborted myocardial infarction in both prehospital and in-hospital thrombolysis.

Design: Retrospective, controlled, observational study.

Setting: Two cities in the Netherlands, one with prehospital thrombolysis, one with in-hospital treatment.

Patients: 475 patients with suspected acute ST elevation myocardial infarction treated before admission to hospital, 269 patients treated in hospital.

Main outcome measures: Aborted myocardial infarction, defined as the combination of subsiding of cumulative ST segment elevation and depression to $<50 \%$ of the level at presentation, together with a rise of creatine kinase of less than twice the upper normal concentration. A stepwise regression analysis was used to test independent predictors for aborted myocardial infarction.

Results: After correction for "unjustified" thrombolysis, $17.1 \%$ of the 468 prehospital treated patients and $4.5 \%$ of the 264 in-hospital treated patients fulfilled the criteria for aborted myocardial infarction. There was no difference in age, sex, risk factors, haemodynamic status, and infarct location of aborted myocardial infarction compared with established myocardial infarction. Time to treatment was shorter in the patients with aborted myocardial infarction (86 versus 123 minutes, $p=0.05$ ). A shorter time to treatment, lower ST elevation at presentation, and higher incidence of preinfarction angina were independent predictors for aborted myocardial infarction. Aborted myocardial infarction had a 12 month mortality of $2.2 \%$, significantly less than the $11.6 \%$ of established myocardial infarction.

Conclusion: Prehospital thrombolysis is associated with a fourfold increase of aborted myocardial infarction compared with in-hospital treatment. A shorter time to treatment, a lower ST elevation, and a higher incidence of preinfarction angina were predictors of aborted myocardial infarction.
\end{abstract}

th n an earlier study using a prehospital strategy, we found that thrombolytic treatment could be instituted on average 60 minutes earlier than in-hospital thrombolysis. ${ }^{1}$ The Reimer and Jennings experiments, where the amount of myocardial damage brought about by temporary closure of a coronary artery was found to be time dependent, ${ }^{2}$ suggested that reversal or abortion of myocardial infarction may have been a factor in our results.

We found an almost threefold higher incidence of aborted myocardial infarction in the prehospital group. ${ }^{1}$ The database of prehospital treated patients has been extended. In the present report the time span between symptom onset and treatment during which abortion of myocardial infarction can be expected was studied, as well as the patients' parameters of aborted myocardial infarction compared with established ST segment elevation myocardial infarction.

\section{METHODS}

Transtelephonic ECGs from patients with chest pain and suspected acute myocardial infarction (duration of chest pain more than 30 minutes and of less than six hours' duration, not relieved by sublingual glyceryl trinitrate) were transmitted to the coronary care unit of one of two Nijmegen hospitals. The ECGs were transmitted by the ambulance staff. More than $0.1 \mathrm{mV}$ ST segment elevation in two anatomically contiguous leads or more than $0.2 \mathrm{mV}$ in leads V1 and V2 confirmed the diagnosis of transmural myocardial ischaemia. A checklist was used to assess the contraindications for thrombolytic treatment, and $30 \mathrm{mg}$ of anistreplase or $10 \mathrm{U}$ of reteplase double bolus was given intravenously; $160 \mathrm{mg}$ of aspirin was also given to the patient to chew. From 1995 to 1999,475 patients were treated before arrival at the hospital: 407 (86\%) with anistreplase and 68 (14\%) with reteplase. Their data were compared retrospectively with those of 269 patients treated between 1995 and 1997 who underwent in-hospital thrombolytic treatment with either 1.5 MU of intravenous streptokinase ( 212 patients, $79 \%$ ) or $100 \mathrm{mg}$ of frontloaded intravenous recombinant tissue plasminogen activator (rt-PA) (57 patients, $21 \%$ ) and intravenous heparin. The latter patients were all treated in an Arnhem hospital that was not then using a prehospital thrombolysis programme.

For this analysis, the names of treated patients were collected by ambulance staff in Nijmegen (using the prehospital strategy), or by the hospital pharmacist of the Arnhem hospital (using in-hospital thrombolysis). In this way all patients treated with fibrinolysis were included in the survey, regardless of the diagnosis at hospital discharge.

Apart from the ambulance recorded ECGs of the prehospital group, ECGs were made on admission to hospital, two hours after treatment, on the following day, a week after admission, and at hospital discharge. All ST segment shifts in

Abbreviations: CK, creatine kinase; GREAT, Grampian Region early anistreplase trial; GUSTO-I, global utilisation of streptokinase and tissue plasminogen activator for occluded coronary arteries; REPAIR, reperfusion in acute infarction, Rotterdam; rt-PA, recombinant tissue plasminogen activator; TIMI, thrombolysis in myocardial infarction 
Table 1 Characteristics of all patients

\begin{tabular}{lccl}
\hline & $\begin{array}{l}\text { Prehospital thrombolysis } \\
(\mathbf{n}=\mathbf{4 7 5})\end{array}$ & $\begin{array}{l}\text { In-hospital thrombolysis } \\
(\mathbf{n}=\mathbf{2 6 9})\end{array}$ & $\mathrm{p}$ Value \\
\hline Mean age (years) & 63 & 62 & $\mathrm{NS}$ \\
Men & $329(69 \%)$ & $192(71 \%)$ & $\mathrm{NS}$ \\
Median time to treatment (minutes) & 98 & 155 & $<0.05$ \\
Transmural ischaemia & & & \\
$\quad$ Anteroseptal & $207(44 \%)$ & $120(45 \%)$ & $\mathrm{NS}$ \\
Inferior & $135(28 \%)$ & $76(29 \%)$ & $\mathrm{NS}$ \\
Inferior + right ventricle & $105(22 \%)$ & $60(23 \%)$ & $\mathrm{NS}$ \\
Lateral & $19(4 \%)$ & $7(3 \%)$ & $\mathrm{NS}$ \\
Other & $9(2 \%)$ & $3(1 \%)$ & $\mathrm{NS}$ \\
Unknown & 0 & $3(1 \%)$ & $\mathrm{NS}$ \\
$\quad$ Unjustified fibrinolysis & $7(1.5 \%)$ & $5(1.9 \%)$ & $\mathrm{NS}$ \\
\hline
\end{tabular}

Table 2 Characteristics of prehospital and in-hospital treated patients, excluding cases of unjustified fibrinolysis

\begin{tabular}{|c|c|c|c|}
\hline & $\begin{array}{l}\text { Prehospital } \\
\text { thrombolysis }(n=468)\end{array}$ & $\begin{array}{l}\text { In-hospital } \\
\text { thrombolysis }(n=264)\end{array}$ & p Value \\
\hline Mean age (years) & 63 & 62 & NS \\
\hline Men & $322(69 \%)$ & $190(72 \%)$ & NS \\
\hline Median time to treatment (minutes) & 97 & 153 & $<0.05$ \\
\hline Mean time to treatment (minutes) & 128 & 183 & NS \\
\hline Maximum time to treatment (minutes) & 305 & 353 & NS \\
\hline \multicolumn{4}{|l|}{ Risk factors } \\
\hline Hypertension & $134 / 459(29.2 \%)$ & $64 / 261(24.2 \%)$ & NS \\
\hline Prior myocardial infarction & $73 / 467(15.6 \%)$ & $29 / 264(11.0 \%)$ & NS \\
\hline Prior angina & $174 / 451(38.6 \%)$ & $105 / 262(40.1 \%)$ & NS \\
\hline Current smoker & $234 / 438(53.4 \%)$ & $136 / 261(52.1 \%)$ & NS \\
\hline Diabetes & $41 / 459(8.9 \%)$ & $29 / 261(11.1 \%)$ & NS \\
\hline \multicolumn{4}{|l|}{ Presentation } \\
\hline Mean heart rate (beats/min) & 75 & 76 & NS \\
\hline Mean systolic blood pressure (mm Hg) & 128 & 132 & NS \\
\hline Mean TIMI risk score & 2.8 & 2.5 & 0.05 \\
\hline Killip class II-IV & $65(14 \%)$ & $15(6 \%)$ & $<0.01$ \\
\hline \multicolumn{4}{|l|}{ Infarct location } \\
\hline Anterior & $201(42.9 \%)$ & $117(44.3 \%)$ & NS \\
\hline Inferior & $135(28.8 \%)$ & $78(29.5 \%)$ & NS \\
\hline Inferior + right ventricle & $105(22.4 \%)$ & $60(22.7 \%)$ & NS \\
\hline Other & $27(5.8 \%)$ & $9(3.4 \%)$ & NS \\
\hline Mean sum of ST elevation on ECG (mV) & 1.7 & 1.5 & NS \\
\hline Abortion of myocardial infarction & $80(17.1 \%)$ & $12(4.5 \%)$ & $<0.05$ \\
\hline
\end{tabular}

the ECGs of both groups were measured by the same observer, using handheld calipers at $80 \mathrm{~ms}$ after the $\mathrm{J}$ point in all 12 leads. This observer was not informed about the cardiac enzyme concentration of the patients.

Blood samples for the determination of cardiac enzymes (creatine kinase (CK) or CK-MB fraction and aspartate aminotransferase) were collected at hospital admission and at eight hour intervals, until two successive drops in the concentration of CK were recorded.

A diagnosis of aborted myocardial infarction was reached as follows: firstly, when the combination of chest pain and transient ECG changes suggested transmural ischaemia; secondly, when CK or CK-MB fraction concentrations did not increase by more than double the normal concentration; and thirdly, when the cumulative ST segment elevation and depression decreased to $<50 \%$ of the value at presentation within two hours of treatment. Two groups are analysed: patients with a diagnosis of aborted myocardial infarction and those with established myocardial infarction. Fibrinolysis was considered to be "unjustified" when CK remained less than twice the upper normal concentrations and when the ST elevation on the ECG at presentation did not change during the 48 hours following thrombolytic treatment.

Stepwise logistic regression analysis was used to test the incidence of aborted myocardial infarction against time to treatment, prior myocardial infarction, prior angina pectoris, hypertension, diabetes, and anterior myocardial infarction, as well as smoking habit, Killip class above I, TIMI (thrombolysis in myocardial infarction) risk score, systolic blood pressure, and heart rate at presentation. Prior angina pectoris was present if patients had been complaining of characteristic chest discomfort within two weeks before presentation. Because of large standard deviations in both the aborted infarction group and the established infarction group, the parameter time to treatment was dichotomised in time to treatment $\leqslant 2$ hours and $>2$ hours.

Statistical analysis was performed using standard methods. The baseline characteristics of the two groups were compared by Student's $t$ test and the frequencies in each group by $\chi^{2}$ analysis. The time intervals of patients treated before or during hospitalisation and of aborted and established groups were compared using the Wilcoxon rank test. Univariate contingency tables were analysed with the uncorrected $\chi^{2}$ test. The level of significance used was 5\%.

\section{RESULTS}

\section{Patient characteristics}

Table 1 shows the basic characteristics of the prehospital and in-hospital treated patients. There were no clinically significant differences between the prehospital and the in-hospital 


\begin{tabular}{|c|c|c|c|}
\hline & $\begin{array}{l}\text { Prehospital thrombolysis } \\
(n=468)\end{array}$ & $\begin{array}{l}\text { In-hospital thrombolysis } \\
(\mathrm{n}=264)\end{array}$ & $\mathrm{p}$ Value \\
\hline Coronary angiography performed & 207 (44.2\%) & $109(41.3 \%)$ & NS \\
\hline No significant disease & $7(3.4 \%)$ & $5(4.6 \%)$ & NS \\
\hline 1 vessel disease & $87(42.0 \%)$ & $52(47.7 \%)$ & NS \\
\hline 2 vessel disease & $49(23.7 \%)$ & $23(22.9 \%)$ & NS \\
\hline 3 vessel disease & 41 (19.8\%) & 19 (17.4\%) & NS \\
\hline Main stem stenosis & $7(3.4 \%)$ & $1(0.9 \%)$ & NS \\
\hline Not available & $16(7.7 \%)$ & $9(8.3 \%)$ & NS \\
\hline \multicolumn{4}{|l|}{ Treatment at 12 months } \\
\hline No intervention & $352(75.2 \%)$ & 202 (76.5\%) & NS \\
\hline $\mathrm{PCI}$ (including rescue PCI) & $73(15.6 \%)$ & $38(14.4 \%)$ & NS \\
\hline Bypass surgery & $43(9.2 \%)$ & $24(9.1 \%)$ & NS \\
\hline Mortality at 30 days & $42(8.9 \%)$ & $18(6.8 \%)$ & NS \\
\hline Mortality at 12 months & 51 (10.9\%) & $25(9.5 \%)$ & NS \\
\hline
\end{tabular}

\begin{tabular}{|c|c|c|c|}
\hline & $\begin{array}{l}\text { Aborted MI } \\
\text { prehospital + } \\
\text { in-hospital }\end{array}$ & $\begin{array}{l}\text { Established MI } \\
\text { prehospital + } \\
\text { in-hospital }\end{array}$ & $p$ Value \\
\hline Number & $92(12.3 \%)$ & $640(87.4 \%)$ & \\
\hline Mean age (years) & 62.0 & $62.7^{7}$ & NS \\
\hline Men & $63(68.5 \%)$ & $449(70.2 \%)$ & NS \\
\hline Median time to treatment (minutes) & 86 & 123 & 0.05 \\
\hline Mean time to treatment (minutes) & 123 & 149 & NS \\
\hline Maximum time to treatment (minutes) & 305 & 353 & NS \\
\hline \multicolumn{4}{|l|}{ Risk factors } \\
\hline Hypertension & $28 / 92(31.1 \%)$ & $170 / 628(27.0 \%)$ & NS \\
\hline Prior myocardial infarction & $12 / 92(13.0 \%)$ & $90 / 639(14.1 \%)$ & NS \\
\hline Prior angina & $44 / 88(50.0 \%)$ & $235 / 625(37.6 \%)$ & $<0.05$ \\
\hline Current smoker & $43 / 87(49.4 \%)$ & $327 / 612(53.4 \%)$ & NS \\
\hline Diabetes & $9 / 92(10.0 \%)$ & $61 / 638(9.6 \%)$ & NS \\
\hline \multicolumn{4}{|l|}{ Presentation } \\
\hline Mean heart rate (beats/min) & 75.3 & 74.9 & NS \\
\hline Mean systolic blood pressure $(\mathrm{mm} \mathrm{Hg})$ & 131 & 129 & NS \\
\hline Mean TIMI risk score & 2.7 & 2.8 & NS \\
\hline Killip class II-IV & $7(7.6 \%)$ & $73(11.4 \%)$ & NS \\
\hline \multicolumn{4}{|l|}{ Infarct location } \\
\hline Anterior & $46(50.0 \%)$ & $274(42.8 \%)$ & NS \\
\hline Inferior & $33(35.9 \%)$ & $178(27.8 \%)$ & NS \\
\hline Inferior + right ventricle & $9(10.0 \%)$ & $156(24.4 \%)$ & NS \\
\hline Other & $4(4.4 \%)$ & $32(5.0 \%)$ & NS \\
\hline Mean sum of ST deviation on ECG $(\mathrm{mm})$ & 14.3 & 19.6 & $<0.05$ \\
\hline Mean sum of ST elevation on ECG $(\mathrm{mV})$ & 12.0 & 17.5 & $<0.05$ \\
\hline Mortality at 30 days & $1(1.0 \%)$ & $59(9.2 \%)$ & $<0.01$ \\
\hline Mortality at 12 months & $2(2.2 \%)$ & $74(11.6 \%)$ & $<0.01$ \\
\hline
\end{tabular}

fibrinolytic treatment groups, except the time to treatment, which was nearly one hour shorter in the prehospital group.

\section{Unjustified fibrinolysis}

Of the 475 prehospital patients, seven (1.5\%) of those treated with a thrombolytic had no rise in cardiac enzymes and, retrospectively, the history and ECGs of these patients suggested no myocardial ischaemia. Two of these patients had gastritis, one had oesophagitis, one had pericarditis, two had early repolarisation on the presenting ECG, and one had left bundle branch block, this being in fact an exclusion criterion for prehospital thrombolysis. In the in-hospital group, five patients (1.9\%) were unjustifiably treated with fibrinolysis, four had coronary artery disease, and one had pericarditis. None of these patients had complications from the fibrinolytic treatment; all were excluded from this analysis.

Table 2 shows the characteristics of the prehospital and in-hospital treated patients, excluding those who received unjustified treatment.
Ninety two patients fulfilled the criteria of aborted myocardial infarction, $12(4.5 \%)$ in the in-hospital treated group and $80(17.1 \%)$ in the prehospital group. In the case of patients who died within 24 hours, peak CK concentration could not be measured. Thus, they could not be included in the aborted myocardial infarction group. In our database, we found 12 patients who died within 24 hours, each with a normal CK concentration at presentation, but in whom peak CK could not be assessed. Among these patients, seven presented with cardiogenic shock. No patient experienced a decrease of pain or ST segment elevation within two hours after presentation so that, although no peak CK was known, none of these patients fulfilled the criteria for diagnosis of aborted myocardial infarction. Three of the in-hospital treated patients died within 24 hours; all had CK-MB fraction two times higher than the upper limit of normal. There were significantly more patients in Killip class II, III, or IV at presentation in the prehospital group, together with a higher mean TIMI risk score. 
Table 5 Characteristics at coronary angiography

\begin{tabular}{llll}
\hline & $\begin{array}{l}\text { Aborted Ml prehospital } \\
+ \text { in-hospital }\end{array}$ & $\begin{array}{l}\text { Established Ml prehospital } \\
+ \text { in-hospital }\end{array}$ & p Value \\
\hline Number & $92(12.3 \%)$ & $640(87.4 \%)$ & NS \\
Coronary angiography performed & $58 / 92(63.0 \%)$ & $258 / 640(40.3 \%)$ & NS \\
No significant disease & $5(8.6 \%)$ & $7(2.7 \%)$ & $N S$ \\
1 vessel & $30(51.7 \%)$ & $109(42.2 \%)$ & NS \\
2 vessel & $12(20.7 \%)$ & $60(23.3 \%)$ & NS \\
3 vessel & $10(17.2 \%)$ & $50(19.4 \%)$ & NS \\
Main stem & 0 & $8(3.1 \%)$ & $24(9.3 \%)$ \\
Not available & $1(1.7 \%)$ & & \\
\hline
\end{tabular}

\begin{tabular}{|c|c|c|c|c|}
\hline Variable & Parameter estimate & SE & Wald $\chi^{2}$ & $p$ Value \\
\hline Time to treatment $\leqslant 2$ hours & -0.6932 & 0.2452 & 7.9905 & 0.005 \\
\hline ST elevation & -0.0668 & 0.0165 & 16.3159 & $<0.0001$ \\
\hline Angina pectoris & 0.05543 & 0.2415 & 5.2709 & 0.0217 \\
\hline Intercept & -0.9201 & 0.2842 & 10.4843 & 0.0012 \\
\hline
\end{tabular}

Five of the prehospital thrombolysis patients presented in Killip IV, of whom four died within 30 days. In the in-hospital group two patients were in Killip IV at presentation; both survived.

\section{Time to treatment and abortion of myocardial infarction}

Eight of the 264 in-hospital thrombolysis patients (3\%) and 89 of the 468 prehospital thrombolysis patients (19\%) were treated within one hour of symptom onset. Eighty of the 468 patients $(17.1 \%)$ belonging to the prehospital group and 12 of the $264(4.5 \%)$ in-hospital group fulfilled the criteria of an aborted myocardial infarction $(\mathrm{p}<0.05)$.

\section{Coronary angiography}

Coronary angiography was performed, at the discretion of the attending cardiologist, in $44.2 \%$ of the prehospital and $41.3 \%$ of the in-hospital treated patients (table 3 ). In both groups, fewer than half of the patients had one vessel disease. Seven prehospital treated patients and five in-hospital treated patients had no significant disease at angiography, although they had extensive dynamic ST segment shifts in the acute phase and a hypokinetic segment in the four patients on whom ventriculography was performed.

\section{Treatment at follow up}

There were no differences in treatment at 12 months' follow up or in mortality between the prehospital and in-hospital treatment groups (table 3).

\section{Patients' characteristics of aborted myocardial infarction}

Table 4 compares patients with aborted myocardial infarction (from both the pre- and the in-hospital groups) with those with established myocardial infarction (from both groups). The median time to treatment of aborted myocardial infarction was 86 minutes, which was significantly shorter than the 123 minutes for established myocardial infarction. Aborted myocardial infarction was not confined to patients who were treated early; $41.3 \%$ of patients with a diagnosis of aborted myocardial infarction were treated after more than two hours.

There were no differences in risk factors, characteristics at presentation, infarct location, or findings at coronary angiography among patients with aborted myocardial infarction (tables 4 and 5), although there was a tendency towards increased incidence of one vessel disease. A stepwise logistic regression analysis showed that time to treatment $\leqslant 2$ hours, a history of angina pectoris, and a lower level of cumulative ST segment elevation at presentation were independent predictors for abortion of myocardial infarction (table 6). Compared with established myocardial infarction, the mortality at 12 months was significantly lower for aborted myocardial infarction.

\section{DISCUSSION}

In this controlled analysis we found a fourfold increase of aborted myocardial infarction associated with prehospital thrombolysis in a large patient group. This result may be explained by a nearly one hour gain in time to treatment.

Our prehospital thrombolysis programme reduces the time to treatment by a median of 56 minutes. However, it shows no mortality benefits. This seems to contradict the meta-analysis of Boersma and colleagues ${ }^{3}$ of 22 thrombolysis trials, which found a highly significant mortality reduction in favour of early treatment and, thus, in favour of prehospital thrombolysis. However, only $11 \%$ of patients in this meta-analysis were randomly assigned within two hours, and the percentage of patients actually treated within two hours would consequently be lower. With our prehospital thrombolysis programme $66 \%$ of patients were treated within two hours. It thus is possible that with prehospital thrombolysis early presenting patients with a worse prognosis are selected. For instance, the GUSTO-I (global utilisation of streptokinase and tissue plasminogen activator for occluded coronary arteries) study, with 41021 patients, found a rise in mortality as time to treatment increased, although mortality of patients treated within one hour of symptom onset was higher than the mortality of those treated between 1-3 hours. ${ }^{4}$ In the GREAT (Grampian Region early anistreplase trial) study, patients with a large infarct and a worse prognosis also tended to seek help earlier, thus confounding the mortality analysis of prehospital thrombolysis trials. ${ }^{5}$ As a result, comparisons made without using a randomisation procedure are bound to result in populations containing larger infarcts, and thus higher mortality rates, for prehospital treated groups, which shows that mortality is a doubtful indicator by which to judge. Furthermore, a larger number of patients than in our study is needed to find a significant reduction in mortality. 
Abortion of myocardial infarction has not previously been suggested as an indicator of the efficacy of prehospital thrombolysis. A highly significant salvage of myocardium in patients treated within two hours after onset of pain was reported using technetium-99m sestamibi injections before thrombolysis, and again at hospital discharge, to assess the myocardium at risk. ${ }^{6}$ The GREAT study found fewer Q wave infarctions in the prehospital group, which may indicate a greater number of aborted infarctions, although this was not specified. ${ }^{5}$ In a substudy, the GREAT authors also found that the proportion of patients showing electrocardiographic reduction of ischaemia up to $50 \%$, compared between home and hospital recordings, was significantly greater in the early than in the late group. Although not mentioned in this study, this is suggestive of aborted myocardial infarction. ${ }^{7}$ The same result was found in 13100 patients treated with either tenecteplase or alteplase and analysed according to resolution of the ST segment on the ECG at presentation. ${ }^{8}$ In this same study, a significantly lower peak CK-MB concentration was observed in patients with complete ST resolution than in patients with partial or no resolution. Furthermore, the extent of ST resolution became significantly less with increasing time to treatment.

By definition, patients with an aborted infarction exhibit dynamic ECG changes, while lacking an enzyme rise, just as do patients who are unjustifiably treated with thrombolysis. Retrospective analysis of ECGs found the same number of unjustified treated patients in our prehospital and hospital groups. This compares well with the $1 \%$ false positive ECGs found in the REPAIR (reperfusion in acute infarction, Rotterdam) study ${ }^{9}$ and the $1 \%$ reported in another study examining inadvertent fibrinolytic treatment. ${ }^{10}$

No visible disease at coronary angiography can be seen in up to $5 \%$ of patients. However, most patients with aborted myocardial infarction do have coronary artery disease and do not differ from patients with established infarction. It may be that infarction can also be aborted by late thrombolytic treatment, the probable cause being myocardial tissue preserved by collateral blood flow before the artery is opened or by intermittent occlusion (stuttering infarction). This phenomenon of intermittent coronary occlusion in acute myocardial infarction has been observed at coronary angiography combined with ST segment monitoring up to five hours after onset of pain, but it was most distinctive in patients presenting within three hours. It is accompanied by improvement of ST segment elevation. In the latter cases, the coronary artery undergoing intermittent occlusion could be kept open with nitrates and intracoronary streptokinase. ${ }^{11}$ This reflects the importance of early treatment for inducing aborted acute myocardial infarction even further.

Apart from time to treatment, a lower amount of ST elevation and a higher incidence of preinfarct angina are independent predictors of aborted myocardial infarction. One must realise that the amount of ST elevation is not a sensitive predictor of the area at risk. Nevertheless, it is likely that timely opening of an occluded coronary artery will result in preservation of myocardial tissue only if the area at risk is not too extensive.

Preinfarction angina has been associated with early coronary thrombolysis in patients with acute ST elevation myocardial infarction. ${ }^{12}$ Furthermore, a prospective study showed significantly fewer 30 day events in patients with onset of angina 24 hours before an ST elevation myocardial infarction. ${ }^{13}$ This has been explained by the phenomenon of preconditioning, ${ }^{14}$ which may explain why in our database preinfarct angina is an independent predictor for aborted myocardial infarction.

\section{Limitations}

This study was not randomised and not performed prospectively. In the thrombolytic situation, time to treatment is all important, so that a study design that assigns patients to either prehospital or in-hospital treatment becomes ethically unjustifiable. Arnhem and Nijmegen are comparable in terms of population, degree of urbanisation, transport times for ambulances, and coronary care unit facilities, the key difference being that no prehospital treatment was available in Arnhem during the study period. In addition, both patient groups had baseline characteristics in reasonable agreement with those reported in the literature, and thus we expect the groups to be comparable.

In both the prehospital and in-hospital treatment groups some patients were treated with streptokinase, rt-PA, or reteplase, in various percentages. Nevertheless, it seems unlikely that the difference in aborted myocardial infarctions was caused by different thrombolytic regimens. This is because more patients in the in-hospital were treated with rt-PA, whereas the incidence of aborted myocardial infarction was lower in this group than in the prehospital group.

\section{Conclusion}

Prehospital thrombolysis in acute myocardial infarction results in a one hour gain in time to treatment and in a fourfold increase in aborted myocardial infarction over that found with in-hospital treatment. A shorter time to treatment, a lower occurrence of ST elevation, and a higher incidence of preinfarction angina were predictors of aborted myocardial infarction. The number of aborted myocardial infarctions may well be a better indicator of the efficacy of early thrombolysis than the currently used mortality rates, especially when small patient cohorts are studied.

\section{ACKNOWLEDGEMENTS}

Sincere thanks are due to the general practitioners, ambulance staff, and cardiologists of both hospitals in Nijmegen for their help in making this study possible. We are also grateful to Mrs Astrid Dekker and the cardiologists of the Rijnstate Hospital in Arnhem for their generous help in collecting and collating patient data. Furthermore, $\mathrm{Mr}$ Theo de Boo, statistician of the Department of Medical Statistics of the University of Nijmegen, was most helpful with the statistical analysis, for which we are very grateful.

\section{Authors' affiliations}

E J P Lamfers, T E H Hooghoudt, D P Hertzberger, A Schut, Department of Cardiology, Canisius-Wilhelmina Hospital, Nijmegen, Netherlands

P W A Stolwijk, Department of Cardiology, Rijnstate Hospital, Arnhem, Netherlands

F W A Verheugt, Department of Cardiology, Heart Centre, Academic Hospital St Radboud, Nijmegen, Netherlands

\section{REFERENCES}

1 Lamfers EJP, Hooghoudt TEH, Uppelschoten A, et al. Effect of prehospital thrombolysis on aborting acute myocardial infarction. Am J Cardiol 1999;84:928-30.

2 Reimer KA, Lowe JE, Rasmussen MM, et al. The wavefront phenomenon of ischaemic cell death. I. Myocardial infarction size vs. duration of coronary occlusion in dogs. Circulation 1977;56:786-94.

3 Boersma E, Maas ACP, Dekkers JW, et al. Early thrombolytic treatment in acute myocardial infarction: reappraisal of the Golden Hour. Lancet 1996;348:771-5.

4 The GUSTO Angiographic Investigators. The effect of tissue plasminogen activator, streptokinase or both on coronary-artery patency, ventricular function, and survival after acute myocardial infarction. N Engl J Med 1993;329:1515-22.

5 Rawles J. Halving of mortality at 1 year by domiciliary thrombolysis in the Grampian Region early anistreplase trial (GREAT). J Am Coll Cardiol 1994;23:1-5.

6 Milavetz J, Giebel DW, Christian TF, et al. Time to treatment and salvage in myocardial infarction. J Am Coll Cardiol 1998;31:1246-51.

7 Trent R, Adams J, Rawles J, on behalf of the GREAT group. Electrocardiographic evidence of reperfusion occurring before hospital admission. Eur Heart J 1994;15:895-7.

8 Fu Y, Goodman S, Chang WC, et al, for the ASSENT-2 investigators. Time to treatment influences the impact of ST-segment resolution on one-year prognosis. Circulation 2001;104:2653-9. 
9 Grijseels EWM, Bouten MM, Lenderink T, et al. Pre-hospital thrombolytic therapy with either alteplase or streptokinase. Eur Heart $J$ 1995; 16:1833-8.

10 Khoury NE, Borzak S, Gokli A, et al. Inadvertent thrombolytic administration in patients without myocardial infarction: clinical features and outcome. Ann Emerg Med 1996;28:289-93.

11 Hackett D, Davies G, Maseri A, et al. Intermittent coronary occlusion in acute myocardial infarction. N Engl J Med 1987;317:1055-9.
12 Andreotti F, Pasceri V, Hackett DR, et al. Preinfarction angina as a predictor of more rapid coronary thrombolysis in patients with acute myocardial infarctions. N Engl J Med 1996;334:7-12.

13 Kloner RA, Shook T, Antman EM, et al, the Timi-9b investigators. Prospective temporal analysis of the onset of preinfarction angina versus outcome. Circulation 1998;97:1042-5.

14 Yellon DM, Dana A. The preconditioning phenomenon. Circ Res 2000;87:543-61.

\section{IMAGES IN CARDIOLOGY}

\section{Surgical resection of multiple right atrial masses in a child with $\beta$ thalassaemia and receiving desferioxamine}

A 14 year old boy was referred for surgical treatment of multiple right atrial masses. At the time of referral he was asymptomatic. His right atrial masses $(\mathrm{T})$ had been discovered incidentally on a routine chest $x$ ray (middle panel) some five months before his referral. He had been diagnosed as having $\beta$ thalassaemia at the age of 2 years and had a splenectomy at 13 years of age. His medications included penicillin, vitamin $\mathrm{C}$, and desferioxamine. His desferioxamine was administered via a Hickman line which was inserted seven years previously. His clinical examination was essentially normal except for his well healed splenectomy scar and the Hickman line which was palpable in the right infraclavicular fossa. Haematological investigations revealed a haemoglobin of $10.3 \mathrm{~g} / \mathrm{dl}$, a white cell count of $12.3 \times 10^{9} \mathrm{~g} / \mathrm{l}$, and platelet count of $166 \times$ $10^{9} \mathrm{~g} /$ l.Transthoracic echocardiography showed a larger right atrial mass which prolapsed through the tricuspid valve (V) (right, upper panel) and also several smaller right atrial masses.

At surgery a large $37 \times 30 \times 16 \mathrm{~mm}$ pedunculated calcified mass was found in the right atrium. This was found to be occluding the orifice of the tricuspid valve. The stalk lay on the atrial septum immediately posterior to the coronary sinus; this stalk was calcified into the tissue wall and was removed as much as possible, as was the mass (right, lower panel). There was an $11 \times 5 \times 2 \mathrm{~mm} \mathrm{sec}$ ond mass on the right atrial wall inferiorly above the inferior vena cava
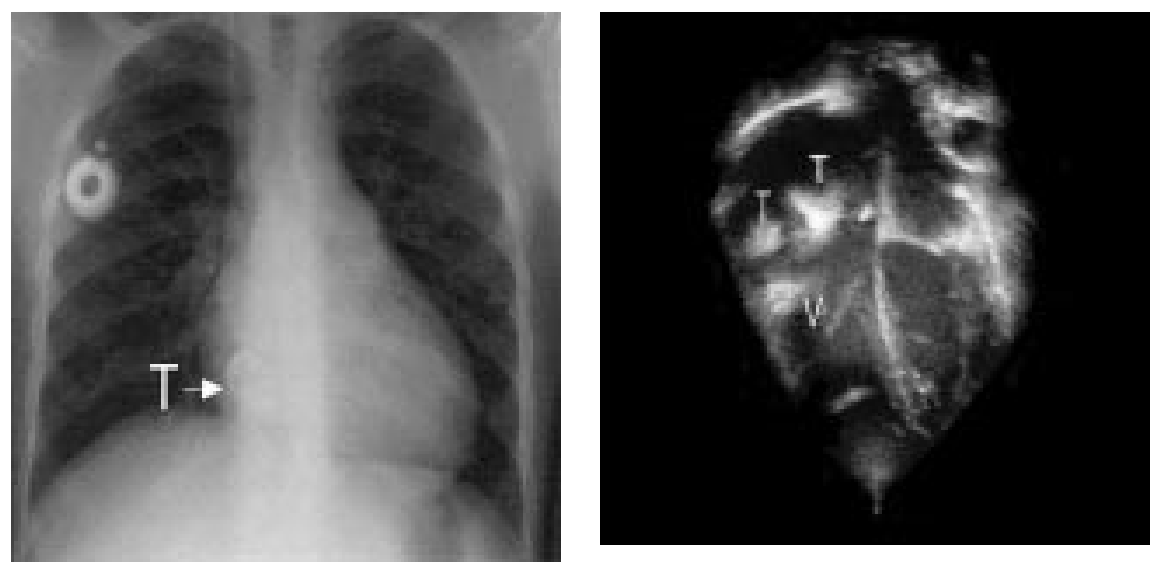

orifice and numerous small calcified masses on the atrial septum. These were all removed. The anterior leaflet of the tricuspid valve was found to have central perforation. This appeared to be where the large atrial mass impacted on the tricuspid valve. This perforation was repaired. Histology of the masses showed them to be calcified thrombus with no signs of iron deposition. The patient's recovery was complicated by a pericardial effusion, which required draining. The patient was discharged home after 14 days and was well two months after final discharge. We conclude that this is an unusual case of dystrophic calcification of multiple atrial thrombi caused by long term insertion of a Hickman line.

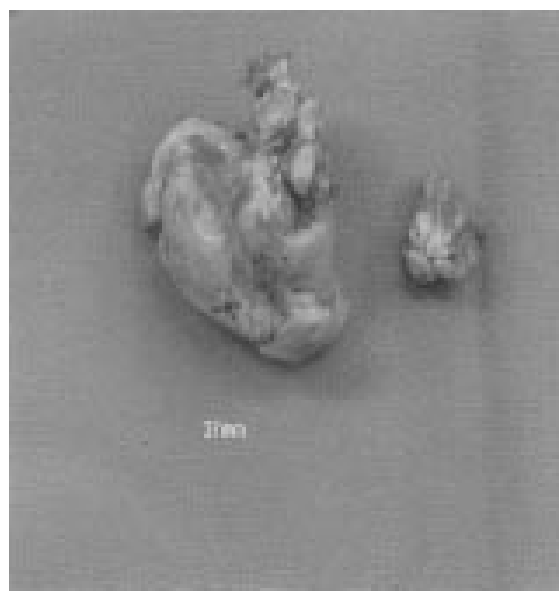

$M$ West

G A Malik

J C S Pollock sdmwesł@yahoo.com 